\title{
Subversion of the chemokine world by microbial pathogens
}

\author{
Adrian Liston ${ }^{1}$ and Shaun McColl ${ }^{2 *}$
}

\begin{abstract}
Summary
It is well known that microbial pathogens are able to subvert the host immune system in order to increase microbial replication and propagation. Recent research indicates that another arm of the immune response, that of the chemokine system, is also subject to this sabotage, and is undermined by a range of microbial pathogens, including viruses, bacteria, and parasites. Currently, it is known that the chemokine system is being challenged by a number of mechanisms, and still more are likely to be discovered with further research. Here we first review the general mechanisms by which microbial pathogens bypass mammalian chemokine defences. Broadly, these can be grouped as viral chemokine interacting proteins, microbial manipulation of host chemokine and chemokine receptor expression, microbial blockade of host chemokine receptor signalling, and the largely hypothetical mechanisms of microbial enhancement of host anti-chemokine networks (including digestion, antagonism, and neutralisation of host chemokines and chemokine receptors). We then discuss the potential results of these interactions in terms of outcome of infection. BioEssays 25:478-488, 2003.

(C) 2003 Wiley Periodicals, Inc.
\end{abstract}

${ }^{1}$ Current address: Immunogenomics Laboratory, The John Curtin School of Medical Research, Australian National University, Australia. ${ }^{2}$ Chemokine Biology Laboratory, Department of Molecular Biosciences, The University of Adelaide, Australia.

Funding agency: Supported by grants from the NH\&MRC (Australia). ${ }^{*}$ Correspondence to: Shaun McColl, Chemokine Biology Laboratory, Department of Molecular Biosciences, The University of Adelaide, Australia. E-mail: shaun.mccoll @ adelaide.edu.au

DOI 10.1002/bies.10273

Published online in Wiley InterScience (www.interscience.wiley.com).

Abbreviations: CCR, CC chemokine receptor; CXCR, CXC chemokine receptor; vCkBP, viral chemokine-binding protein; vCkR, viral chemokine receptor homolog; vCk, viral chemokine homolog; vCC, viral CC chemokine homolog; vCXC, viral CXC chemokine homolog; HHV, human herpes virus; huCMV, human cytomegalovirus; muCMV, murine cytomegalovirus; SCMV, simian cytomegalovirus; HIV, human immunodeficiency virus; MCP, monocyte chemotactant protein; MIP, macrophage inflammatory protein; IL, interleukin; GRO, growth related oncogene; IFN, interferon; interleukin-11-receptor- $\alpha$-locus chemokine.

\section{Introduction-the chemokine gene family}

During evolution of the host defence strategies, microbial pathogenicity mechanisms have been co-evolving to counter every defence. High mutation rates and sophisticated antigenic shift allow direct evasion from the highly specific adaptive arm of the immune response. ${ }^{(1)}$ In addition, microbial pathogens have been able to directly disable immune components, including cytokine networks (for example neutralising the anti-viral properties of interferon), antigen presentation (for example reducing the presentation of microbial antigen on MHC class I), the complement cascade, and components of cellular defence. ${ }^{(2,3)}$

Another important constituent of the host immune system is the chemokine network. Chemokines, or chemotactic cytokines, are the largest known group of cytokines. There are around 40 known chemokines, and 20 chemokine receptors. Chemokines are divided into four structural families, based on the spacing of the conserved cysteine residues. The $\mathrm{CC}$ and $\mathrm{CXC}$ families are the largest, with the $\mathrm{C}$ and $\mathrm{CX}_{3} \mathrm{C}$ families consisting of only a few members. The relationship between chemokines and chemokine receptors is highly promiscuous, with most receptors binding many chemokines, and most chemokines binding several receptors (see reviews 4,5 and Table 1).

The best-understood role of chemokines is the promotion of leukocyte migration. All classes of leukocytes express various chemokine receptors, and are thus capable of migrating along a chemokine gradient. These gradients can be soluble or fixed (via the glycosaminoglycan binding properties of many chemokines). ${ }^{(6,7)}$ However, the role of chemokines is not limited to chemotaxis, indeed, in the case of several members, chemotaxis may not be the major biological function. Chemokines also function in Th-1/2 differentiation, $T$ cell costimulation, granulocyte activation, gene transcription, mitogenesis, apoptosis, haematopoiesis, angiogenesis and development. ${ }^{(8)}$

Chemokines, as a crucial host immune system, have not been ignored by microbial pathogens. In fact, a strong argument for the importance of chemokines in immunity is the extent to which pathogens have evolved mechanisms to counter the chemokine network. The creative mechanisms with which these pathogens penetrate our chemokine defence involve not only direct immune evasion, but also increased microbial replication and propagation. 
Table 1. The four chemokine subfamilies

\begin{tabular}{|c|c|c|c|}
\hline Family & Human ligand & Mouse ligand & Major receptors \\
\hline \multicolumn{4}{|l|}{ CXC Family } \\
\hline \multicolumn{4}{|c|}{$\mathrm{ELR}^{+}$subfamily } \\
\hline CXCL1 & GRO/MGSA- & GRO/KC? & CXCR2>CXCR1 \\
\hline CXCL2 & GRO/MSGA- & GRO/KC? & CXCR2 \\
\hline CXCL3 & GRO/MSGA- & GRO/KC? & CXCR2 \\
\hline CXCL5 & ENA-78 & LIX? & CXCR2 \\
\hline CXCL6 & GCP-2 & CK-3 & CXCR1, CXCR2 \\
\hline CXCL7 & NAP-2 & ? & CXCR2 \\
\hline CXCL8 & IL-8 & ? & CXCR1, CXCR2 \\
\hline \multicolumn{4}{|c|}{$\mathrm{ELR}^{-}$subfamily } \\
\hline CXCL4 & PF4 & PF4 & $?$ \\
\hline CXCL9 & Mig & Mig & CXCR3 \\
\hline CXCL10 & IP-10 & IP-10 & CXCR3 \\
\hline CXCL11 & I-TAC & $?$ & CXCR3 \\
\hline CXCL12 & SDF-1/ & SDF-1 & CXCR4 \\
\hline CXCL13 & $\mathrm{BLC} / \mathrm{BCA}-1$ & $\mathrm{BLC} / \mathrm{BCA}-1$ & CXCR5 \\
\hline CXCL14 & BRAK/bolekine & BRAK & $?$ \\
\hline (CXCL15) & $?$ & Lungkine & $?$ \\
\hline CXCL16 & Sexckine & Sexckine & CXCR6 \\
\hline \multicolumn{4}{|l|}{ CC Family } \\
\hline CCL1 & I-309 & TCA-3, P500 & CCR8 \\
\hline CCL2 & MCP-1/MCAF & JE? & CCR2 \\
\hline CCL3 & MIP-1/LD78 & MIP-1 & CCR1, CCR5 \\
\hline CCL4 & MIP-1 & MIP-1 & CCR5 \\
\hline CCL5 & RANTES & RANTES & CCR1, CCR3, CCR5 \\
\hline (CCL6) & ? & C10, MRP-1 & ? \\
\hline $\mathrm{CCL} 7$ & MCP-3 & MARC? & CCR1, CCR2, CCR3 \\
\hline CCL8 & MCP-2 & MCP-2? & CCR3 \\
\hline (CCL9/10) & $?$ & MRP-2, CCF18 MIP-1 & $?$ \\
\hline CCL11 & Eotaxin & Eotaxin & CCR3 \\
\hline (CCL12) & ? & MCP-5 & CCR2 \\
\hline CCL13 & MCP-4 & $?$ & CCR2, CCR3 \\
\hline CCL14 & $\mathrm{HCC}-1$ & ? & CCR1 \\
\hline CCL15 & HCC-2/Lkn-1/MIP-1 & ? & CCR1, CCR3 \\
\hline CCL16 & HCC-4/LEC & LCC-1 & CCR1 \\
\hline CCL17 & TARC & TARC & CCR4 \\
\hline CCL18 & DC-CK1/PARC AMAC-1 & $?$ & $?$ \\
\hline CCL19 & MIP-3/ELC/exodus-3 & MIP-3/ELC/exodus-3 & CCR7 \\
\hline CCL20 & MIP-3/LARC/exodus-1 & MIP-3/LARC/exodus-1 & CCR6 \\
\hline CCL21 & 6Ckine/SLC/exodus-2 & 6Ckine/SLC/exodus-2 & CCR7 \\
\hline CCL22 & MDC/STCP-1 & $A B C D-1$ & CCR4 \\
\hline CCL23 & MPIF-1 & ? & CCR1 \\
\hline CCL24 & MPIF-2/Eotaxin-2 & ? & CCR3 \\
\hline CCL25 & TECK & TECK & CCR9 \\
\hline CCL26 & Eotaxin-3 & ? & CCR3 \\
\hline CCL27 & CTACK/ILC & ALP/CTACK/ILC/ESkine & CCR10 \\
\hline CCL28 & CCL28 & CCL28 & CCR10 \\
\hline \multicolumn{4}{|l|}{ C Family } \\
\hline $\mathrm{XCL1}$ & Lymphotactin/SCM-1/ATAC & Lymphotactin & XCR1 \\
\hline XCL2 & SCM-1 & ? & XCR1 \\
\hline \multicolumn{4}{|l|}{$\mathrm{CX}_{3} \mathrm{C}$ Family } \\
\hline $\mathrm{CX}_{3} \mathrm{CL} 1$ & Fractalkine & Neurotactin & $\mathrm{CX}_{3} \mathrm{CR} 1$ \\
\hline
\end{tabular}

\section{Mechanisms involved in the highjack of the chemokine system}

Microbial organisms have been successful in subverting the chemokine system in a number of different ways, often using mechanisms derived from host pathways. In general, these mechanisms can be divided into four main groups-(a) production of a microbial protein able to directly interact with the chemokine system, (b) altered expression of chemokines or receptors, (c) blockage of the signalling pathway of chemokine receptors, or (d) sabotage of host chemokine proteins.

\section{Microbial proteins}

Viruses have been demonstrated to subvert the host immune system through the production of viral proteins able 
to interact with the host's immune system. ${ }^{(9)}$ These are often homologs of host proteins, but several are unique to the virus (presumably where no host gene exists that could be easily modified). ${ }^{(10)}$ In the case of proteins altering the chemokine system, viral products have been made from three sources-homologs of chemokines (vCk), homologs of chemokine receptors (vCkR), and unique viral products able to bind chemokines ( $\mathrm{vCkBP}$ ). Most viral chemokine modulators are expressed by large DNA viruses, especially herpes viruses and poxviruses; ${ }^{(10)}$ although the retrovirus HIV-1 also contains a viral chemokine homolog${ }^{(11)}$ (see Table 2). In addition, recent evidence suggests that the bacterium

Table 2. Chemokine modulators encoded by viruses

\begin{tabular}{|c|c|c|c|c|}
\hline Viral protein & Viral homologs & Host homolog & Putative function & Ref \\
\hline \multicolumn{5}{|c|}{ Viral chemokine-binding proteins } \\
\hline \multirow[t]{2}{*}{ Poxvirus vCkBP-I } & M-T7 (Myxoma virus) & IFN- $\gamma \mathrm{R}$ & $\begin{array}{l}\text { C, CC, CXC chemokine inhibitor via } \\
\text { GAG binding site }\end{array}$ & (10) \\
\hline & S-T7 (Shope fibroma virus) & & & \\
\hline \multirow[t]{6}{*}{ Poxvirus vCkBP-II } & B29R/C23L (Vaccina virus) & $N / A$ & Broad spectrum CC chemokine inhibitor & $(78)$ \\
\hline & M-T1 (Myxoma virus) & & & \\
\hline & S-T1 (Shope fibroma virus) & & & \\
\hline & RPV/35kDa protein (Rabbitpox virus) & & & \\
\hline & G3R/35kDa protein (Smallpox virus) & & & \\
\hline & DIL/H5R (Cowpox virus) & & & \\
\hline \multirow[t]{2}{*}{ Herpesvirus vCkBP } & M3 (Murine gammaherpesvirus 68) & $\mathrm{N} / \mathrm{A}$ & $\mathrm{C}, \mathrm{CC}, \mathrm{CXC}, \mathrm{CX}_{3} \mathrm{C}$ chemokine inhibitor & $(30)$ \\
\hline & \multicolumn{3}{|c|}{ Viral chemokine receptors } & \\
\hline Poxvirus vCXCR & K2R (Swinepox virus) & CXCR & $?$ & $(79)$ \\
\hline Poxvirus vCCR & Q2/3L (Capripox virus) & CCR & $?$ & \\
\hline \multirow[t]{5}{*}{ Herpesvirus vCXCR } & ORF74 (HHV-8) & CXCR2 & $\begin{array}{l}\text { Functional CXC receptor Constitutive } \\
\text { and agonist-induced signalling }\end{array}$ & $(17) ;(76) ;(30)$ \\
\hline & ORF74/ECRF3 (Herpesvirus saimiri) & & & \\
\hline & ORF74 (Murine gammaherpesvirus & & & \\
\hline & 68) & & & \\
\hline & ORF74/E1/E6 (Equine herpesvirus 2) & & & \\
\hline \multirow[t]{5}{*}{ Herpesvirus vCCR-1 } & US28 (huCMV) & CCR1 & Functional CCR (CC chemokines) & $(19) ;(80)$ \\
\hline & & & Sequesters chemokines & \\
\hline & & & Constitutively active signalling & \\
\hline & US27 (huCMV) & & & \\
\hline & $\begin{array}{l}5 \text { putative homologs (sCMV-derived } \\
\text { stealth virus) }\end{array}$ & & & \\
\hline \multirow[t]{4}{*}{ Herpesvirus vCCR-2 } & U12 (HHV6) & CCR & Functional CC chemokine receptor & $(81)$ \\
\hline & U12 (HHV7) & & & \\
\hline & UL33 (huCMV) & & & \\
\hline & M33 (muCMV) & & & \\
\hline \multirow[t]{5}{*}{ Herpesvirus vCCR-3 } & U51 (HHV6) & CCR & Binds CC chemokines & (38) \\
\hline & U51 (HHV-7) & & & \\
\hline & UL78 (huCMV) & & & \\
\hline & M78 (muCMV) & & & \\
\hline & \multicolumn{3}{|c|}{ Viral chemokines } & \\
\hline Retrovirus vCCL & Tat (HIV-1) & MCP & CCR2/3 agonist & $(11)$ \\
\hline Poxvirus vCCL & MC148R/vMCC-1 & CCL27 & Promiscuous receptor antagonist & $(18)$ \\
\hline \multirow[t]{4}{*}{ Herpesvirus vCXCL } & vCXCL-1/UL146 (huCMV) & $\mathrm{CXC}$ & Potent CXCR2 agonist & $(15)$ \\
\hline & vCXCL-2/UL147 (huCMV) & $\mathrm{CXC}$ & $?$ & \\
\hline & $\begin{array}{l}3 \text { putative vGRO- } \alpha / \text { MGSA } \\
\text { (sCMV-derived stealth virus) }\end{array}$ & GRO- $\alpha$ & $?$ & (82) \\
\hline & vlL-8 (Marek's Disease Virus) & IL-8 & Chicken mononuclear cell chemotaxis & (14) \\
\hline \multirow[t]{6}{*}{ Herpesvirus vCCL } & VMIP-I/K6 (HHV8) & $\mathrm{MIP}-1 \alpha$ & CCR8 agonist & $(71)$ \\
\hline & VMIP-II/K4 (HHV8) & $\mathrm{MIP}-1 \alpha$ & $\begin{array}{l}\text { CCR } 1 / 2 / 5 \text { antagonist, } \mathrm{CCR} 3 / 8 \text { and } \\
\text { CXCR2 agonist }\end{array}$ & (70) \\
\hline & U83 (HHV6) & $\mathrm{MIP}-1 \alpha$ & Mononuclear cell chemoattractant & $(74)$ \\
\hline & VMIP-III/BCK (HHV8) & MIP-1 $\beta$ & $?$ & $(17)$ \\
\hline & MCK-1/m131 (muCMV) & $\mathrm{CC}$ & CCR agonist & $(83,84)$ \\
\hline & MCK-2 (muCMV) & & & \\
\hline
\end{tabular}


Mycobacterium avium also expresses a chemokine homolog to $\mathrm{MCP}-1{ }^{(12)}$

Viral chemokines (vCk). Viral homologs of host chemokines can be captured CC or CXC chemokines (such as VMIPI/II/III and VIL-8 respectively). The captured genes have been modified, and presumably allow the virus a selective advantage. The viral homologs often have a much more promiscuous receptor range than the original host chemokine, and also may have altered receptor-activation properties. ${ }^{(13)}$ They are able to function in two major manners as depicted in Fig. 1b,c. First of all, vCks can be fully functional chemokines able to activate the host receptor in the normal manner (Fig. 1b). In this case, the viral product directly mimics host function, and activates host receptors that would normally be inactive due to a lack of endogenous ligand. Examples of this first mechanism are vIL-8 (IL-8R agonist, Ref. 14), vCXC1 (CXCR2 agonist, Ref. 15), vMIPI (CCR8 agonist, Ref. 16), and vMIPII (CCR3, CCR8 and CXCR2 agonist, Refs. 13,17). Secondly, vCks can be dysfunctional homologs, capable of binding the chemokine receptor without activating it, resulting in receptor antagonism (Fig. 1, panel c). Examples of this second mechanism are MC148R (a CC chemokine homolog able to antagonise many $\mathrm{CC}$ and CXC receptors, Ref. 18), and vMIPII (CCR1, CCR2, CCR5, CCR8, CXCR4, XCR1 and CCR10 antagonist, Refs. 13,18). VMIPII is able to function in both of these manners, acting as an agonist for some receptors and an antagonist for others. ${ }^{(16)}$

Viral chemokine receptors (vCkR). Poxviruses and herpesviruses have captured several CC and CXC chemokine receptors. Expression of these viral receptor homologs on infected cells can serve several purposes. Firstly, expression of the receptor may allow the infected cell to migrate in response to endogenous chemokines that it would otherwise be unable to recognise (Fig. 1b). For example, the CMV vCCR-1 US28 may allow the infected cell to migrate along endogenous chemokine gradients of MIP- $1 \alpha, \mathrm{MIP}-1 \beta$, MCP-1 and RANTES. ${ }^{(19)}$ Secondly, the vCkR may act as a decoy receptor to prevent the activity of the endogenous chemokine. Decoy receptors can act in cis or trans. Cis decoy receptors act by binding endogenous chemokine to prevent it from binding cellular receptors on the surface of the infected cell. If the vCkR is unable to signal, the infected cell is prevented from responding to the appropriate stimuli (see Fig. 1c). Trans decoy receptors act by binding endogenous chemokines from the environment, internalising them via receptor-mediated endocytosis, and destroying them. For example, CMV vCCR-1 US28 is able to intensely sequester RANTES and MCP-1 through continuous internalisation, resulting in a modification of the chemokine environment. ${ }^{(9)}$ Thirdly, the vCkR can have constitutive signalling activity. Constitutively active vCkRs have been implicated in stimulat-
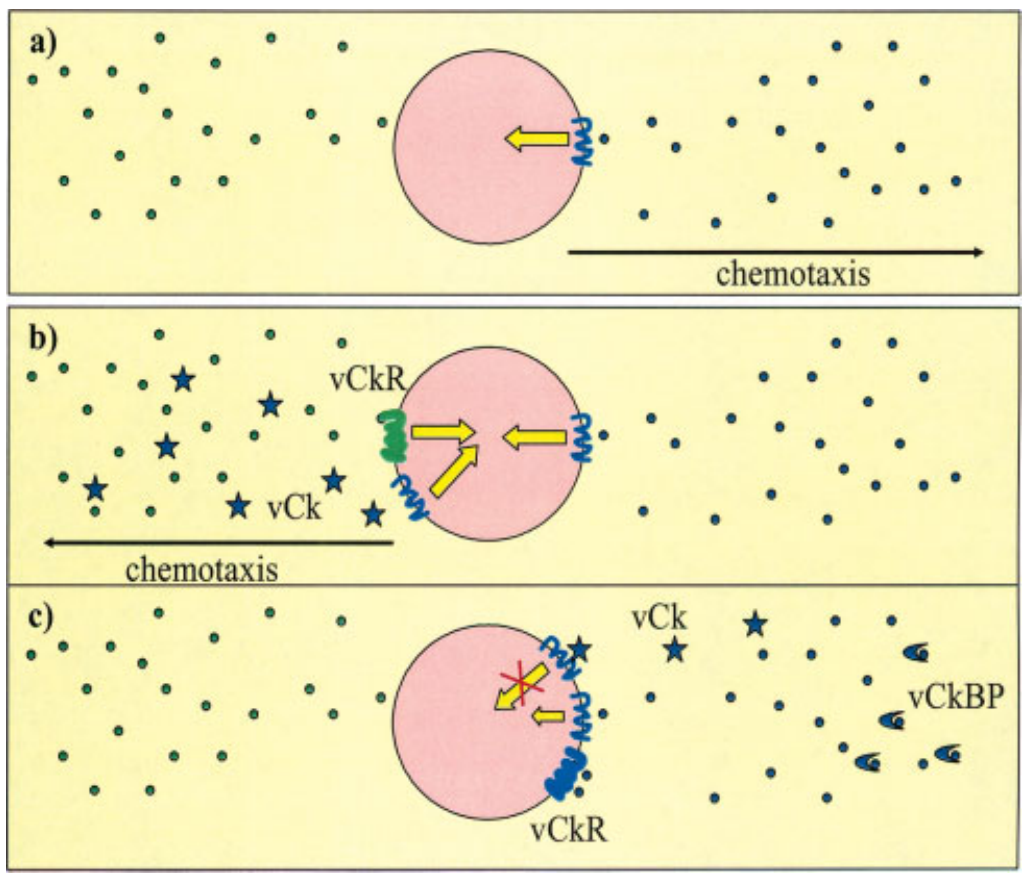

Figure 1. Mechanisms of dysregulation of host leukocyte chemotaxis by vCk, vCkR and vCkBP. Normal uninfected state: a) in the homeostatic situation, cellular expression of endogenous chemokine receptors (n) activates signal transduction $(\Longleftrightarrow)$ allowing chemotaxis towards appropriate ligands $(\bullet)$, but not inappropriate ligands (॰). Infected host: b) expression of vCkR (w) can allow migration towards an inappropriate endogenous ligand (॰), while expression of vCk ( $\star$ ) can stimulate endogenous chemokine receptors (nv) to follow viral gradients, in both cases leading to inappropriate migration; c) vCk ( $\star$ ) can also act as receptor antagonists for endogenous receptors (Mv), while vCkR (Mv) can act as decoy receptors (without signal transduction), and vCkBP $(\ll)$ can prevent binding of endogenous ligands ( $\bullet$ ) to their endogenous receptor (m) in all cases reducing migration towards the endogenous ligand. 
ing angiogenesis, ${ }^{(20,21)}$ oncogenesis ${ }^{(22,23)}$ and cellular activation. ${ }^{(24)}$ CMV vCCR-1 US28 gives constitutive activation of $\mathrm{Gq} / 11$, resulting in phospholipase $\mathrm{C}$ and NF- $\kappa$ B activation. ${ }^{(24)}$ KSHV vCCR-2 ORF-74 is constitutively active through the phosphoinositide-inositoltrisphosphate-protein kinase C pathway, giving oncogenic transformation and inducing the secretion of vascular endothelial growth factor for angiogenesis. ${ }^{(25,26)}$ The constitutive activity of this $v C k R$ is influenced by the binding of endogenous chemokines (inhibited by IP. $10^{(27)}$ or SDF-1 $\alpha,{ }^{(22)}$ stimulated by IL-8 or GRO- $\alpha$, Ref. 20 ). The function of many of the putative vCkRs is still unknown, but may follow one or more of these mechanisms.

Viral chemokine-binding proteins (vCkBP). There are several examples of viral cytokine-binding proteins produced by the viral capture of host receptor genes and modification into a soluble form. With single-pass transmembrane receptors, modification requires only the truncation of the transmembrane domain in order to produce a soluble receptor (this is often used by the host as a post-translational modification to reverse the function of a receptor, such as with the TNF $\alpha$ receptor). ${ }^{(28)}$ However, since chemokine receptors are seven-pass serpentine transmembrane structures, they are not easily modified to create a soluble form of receptor. Therefore, viral chemokine-binding proteins (vCkBP) are not homologs of host chemokine receptors; rather they are unique viral products with no host homolog (examples include poxvirus vCkBP-II or herpesvirus vCkBP). ${ }^{(29)}$ Another example is the poxvirus vCKBP-I protein, which is a modified soluble homolog of the host IFN $\gamma$ receptor, that binds various chemokines as well as IFN $\gamma .{ }^{(10)}$

There are two mechanisms by which vCkBPs may function. The first is simple neutralisation of the bound chemokine (see Fig. 1c). Poxvirus vCkBP-II and herpesvirus vCkBP bind chemokines in such a manner as to prevent the function of the chemokine-either by preventing binding to the receptor, or by preventing activation of the receptor. ${ }^{(29-31)}$ The second mechanism is displayed by poxvirus vCkBP-I. Poxvirus vCkBP-I is able to bind a wide range of chemokines through binding the conserved glycosaminoglycan (GAG) binding domain. ${ }^{(10)}$ By binding the chemokines in such a manner, it prevents them from binding the extracellular matrix, and therefore prevents the formation of a stable chemokine gradient $^{(16,30)}$. Poxvirus vCkBP-I is also able to function in the first manner by direct neutralisation. ${ }^{(10)}$

\section{Altering expression of chemokines or chemokine receptors}

Another way in which microbes are capable of subverting the chemokine network is through the promotion or suppression of host chemokine or chemokine receptor expression. This is a common technique employed by microorganisms in escaping various host immune responses (such as the downregulation of $\mathrm{MHC}$ class I genes in virally infected cells, Ref. 3). Altering the expression level of chemokines or receptors can be achieved through the manipulation of transcription factors. For example, intracellular infection with $\mathrm{CMV}^{(32)}$ or $\mathrm{EBV}$ (via LMP1, Ref. 33), or contact with soluble factors from Helicobacter pylori, ${ }^{(34)}$ Bordetella pertussis ${ }^{(35)}$ or Clostridium difficile (via Toxin A, Ref. 36,37) results in the activation of transcription factors $N F-\kappa B$ and $A P-1$. This results in the upregulation of IL-8. ${ }^{(36)}$

Since altering transcription factors may have an effect on multiple genes, it is often difficult to determine which of the products are modified to microbial advantage and which are simply altered in a 'bystander' fashion. In addition, it can be difficult to tease apart expression altered by the microbe, from expression altered by the host cell as an anti-microbial response. In some cases, both factors may even be complementary. However, in at least one of the examples above, CMV induction of IL-8, it is clear that the upregulation of chemokines can be important for microbial pathogenesis. With $\mathrm{CMV}$ infection, IL-8 has been shown to have a number of critical functions during infection (detailed later in the review), emphasised by the viral production of vCXCL1, which acts as a CXCR2 agonist with similar potency to IL-8. Another confirmed role for chemokine transcriptional modification is the downregulation of RANTES by HHV6-infected cells. ${ }^{(38)}$ Infection with HHV6 results in the production of vCCR-3 (US51). As well as being able to sequester RANTES and other CC chemokines, US51 activation downregulates the transcription of RANTES. ${ }^{(38)}$ It has been postulated that this twopronged reduction of RANTES has a role in immune evasion or in the recruitment of permissive cells.

\section{Blocking chemokine receptor signalling pathways}

Another mechanism by which microbial organisms can reduce the host chemotactic response is to prevent the signalling that occurs when a chemokine binds its receptor. In order for the chemokine to have an effect, binding must be transmitted from the receptor to the cell via the activation of G-protein signalling pathways. The bacteria Bordetella pertussis is able to prevent this signalling through the virulence factor Pertussis Toxin (PT). PT is an ADP ribosyltransferase able to block signalling from the G-protein coupled to 7-transmembrane receptors. ${ }^{(39)}$ PT has many effects on the host, and it is therefore difficult to determine which are important for pathogenicity; however, the inhibitory effect of PT on chemokine signalling may be crucial for the success of this pathogen.

Another example of blocking CkR signalling may be that of Influenza A nucleoprotein. Influenza A nucleoprotein contains a region of homology to a host protein able to prevent neutrophil activation, and the purified nucleoprotein is able to inhibit neutrophil chemotaxis (including towards IL-8) and activation. ${ }^{(40,41)}$ Currently the molecular mechanism is uncertain,

\section{BioEssays 25.5}


but the nucleoprotein may work by binding CR3 and altering $\mathrm{Ca}^{2+}$ homeostasis, therefore preventing optimal signalling from CXCR1/2 in response to IL-8. ${ }^{(41)}$

\section{Manipulation of host products}

A final mechanism by which microbes may alter the host chemokine system is through exploitation of host antichemokine programs (Fig. 2). As yet, this proposed mechanism is hypothetical, but as host mechanisms are already in place, it would be surprising if microbes have not evolved the ability to take advantage of these systems. In particular it would be expected that various bacteria and parasites would function in such a manner, as they do not appear to have the range of vCk, vCkR and vCkBPs found in viruses (which are more capable of capturing host genes for modification).

\section{Generation of soluble glycosaminoglycans} (GAG). The first host anti-inflammatory mechanism that may be exploited by bacteria and parasites is the neutralisation of chemokines through stimulating the production of soluble GAG in the host. As previously mentioned, many chemokines contain a GAG-binding domain, which allows the formation of stable chemokine gradients in the extracellular matrix. ${ }^{(6,7)}$ However, soluble GAG still retains chemokine binding, without being fixed to form a stable gradient. Soluble GAG components such as heparin, heparan sulfate, chondroitin sulfate and dermatan sulphate are able to form complexes with a wide range of chemokines, preventing the formation of a stable gradient and modulating receptor binding. ${ }^{(42,43)}$ This rather non-specific binding of chemokines has been shown to have an anti-inflammatory effect. ${ }^{(42)}$ After infection, macrophages and fibroblasts activate matrix metallo-proteases (MMPs) and thus allow the enzymatic degradation and de novo synthesis of the extracellular matrix
(ECM). ${ }^{(44)}$ Products generated during this degradation include soluble components of GAG, which may be one of the mechanisms involved in host downregulation of the inflammatory response.

In effect, this mechanism has been mimicked by poxviruses, with the production of the vCkBP T7, which is able to bind chemokines through a GAG-binding domain. ${ }^{(10)}$ However, bacteria do not appear to produce any CkBPs and, rather than mimic the effect of soluble GAG, they may instead directly use host soluble GAG components to dampen immunity. Several species of bacteria, and all multicellular eukaryotic parasites, express matrix-remodelling enzymes that are able to cleave the GAG-protein linkage site, creating soluble GAG components. ${ }^{(45)}$ For example, Flavobacterium heparinum, Proteus vulgaris and Arthrobacter aurescens produce several Heparinases and Chondroitinases. ${ }^{(45-47)}$ It is unknown as yet whether the soluble GAG produced in these reactions is capable of disrupting the chemokine network.

To modify the chemokine network in such a way, it is not necessary for the bacteria to produce enzymes that directly release soluble GAG, as the host remodelling enzymes are present in a latent state. Instead, a microbial product could indirectly generate soluble GAG through the triggering of the host protease cascade. For example, Staphylococcus aureus expresses a plasminogen receptor that is able to bind and activate host plasmin, triggering the proMMP-1 to be degraded into active MMP-1, ${ }^{(48)}$ and Treponema lecithinolyticum is able to activate host MMP-2. ${ }^{(49)}$

Alternatively, a microbe could upregulate host MMPs or downregulate host TIMPs (MMP inhibitors) to achieve the same effect. There are several examples of bacteria specifically altering the expression of host MMPs (Microbacterium tuberculosis-infected monocytes express MMP-9, Ref. 50)

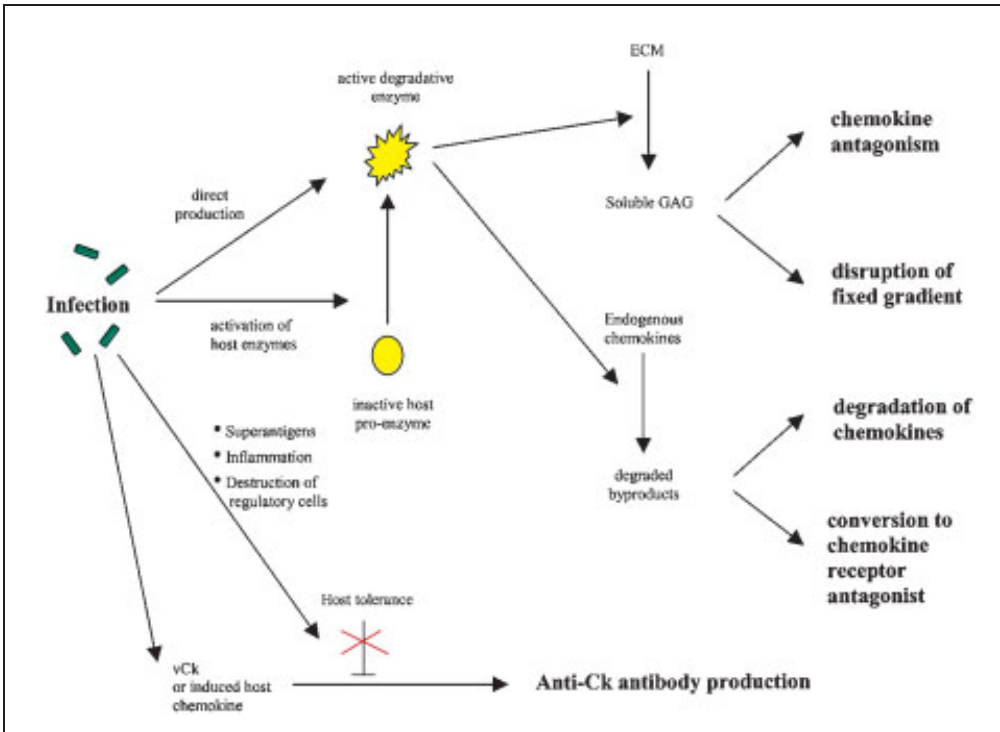

Figure 2. Microbial induction of host anti-chemokine mechanisms. Microbial infections can result in the direct production of degradative enzymes, or the activation of host degradative enzymes, which can act on the host extracellular matrix, or on endogenous chemokines. Disruption of the ECM destroys fixed chemokine gradients, and soluble glycosaminoglycans can nonspecifically bind host chemokines, preventing the host chemokines binding to intact ECM in addition to inhibiting receptor binding. Degradation of endogenous chemokines directly inactivates chemokines, and, in addition, by-products that cannot activate chemokine receptors but which retain receptor binding, can act as receptor antagonists. Microbial infections could hypothetically induce anti-chemokine antibodies to neutralise host chemokines, via expression of viral chemokine homologs or enhanced expression of host endogenous chemokines, simultaneous with transient perturbations in host tolerance mechanisms. 
and broad-based inflammatory factors such as TNF- $\alpha$, IL-1 and LPS are all able to alter the expression patterns of both MMPs and TIMPs. ${ }^{(51)}$

Despite these examples, no studies have yet been conducted to identify the microbial-induced production of soluble GAG components capable of chemokine neutralisation. Furthermore, any detected soluble GAG production could simply be a by-product, as microbial-induced ECM degradation has its own role in pathogenesis. However, if ECM degradation were shown to be partially carried out in order to produce soluble GAG, the resulting neutralisation of chemokines would represent subversion of the host anti-inflammatory program.

Digestion of host chemokines. The second of these host anti-chemokine programs is the digestion of functional chemokines. Chemokine digestion by host proteases (including serine proteases and MMPs) has been shown to enhance chemokine activity (e.g. MMP-9 activates IL-8 by amino-terminal clipping, Ref. 44), destroy chemokine function (e.g. MMP-2 cleaves SDF- $1 \alpha / \beta$ at aa $4-5$, inactivating it, Ref. 52) or to turn chemokines into receptor antagonists. ${ }^{(53)}$ Recently, it has been shown that host MMP-2 is able to produce an N-terminal truncation of native MCP-3 by partial digestion into 5-76 MCP-3. ${ }^{(53)}$ The resulting product retains receptor-binding activity, but sustains the loss of ability to activate receptors, therefore acting as a receptor antagonist rather than agonist for CCR1/2/3. ${ }^{(53)}$ Other chemokines may also be converted to receptor antagonists, as synthetically produced N-terminal chemokine truncations of MIP-3 $\alpha$, MCP-1, MIP-3 $\beta$, RANTES and SDF all act as receptor antagonists (Refs. 54,55 and unpublished data). Active digestion of chemokines by host MMPs could therefore represent an anti-inflammatory program, which both destroys the chemokine gradient, and produces chemokine receptor antagonists.

As bacteria and parasites produce many proteolytic enzymes, future investigation may find products that contain the same specificity of degradation, and are therefore able to enhance the chemotactic ability of chemokines, destroy chemokine gradients or produce receptor antagonists. One example comes from the hookworm Necator americanus, which secretes a metalloprotease capable of inactivating eotaxin. ${ }^{(56)}$ Alternatively, rather than directly encoding the specific protease, microbes may work by invoking the relevant host protease. ${ }^{(4)}$ For example, by triggering neutrophil degranulation, CMV indirectly releases MMP-9, which activates IL-8, to enhance neutrophil recruitment. ${ }^{(57)}$ Alternatively, HIV induces the expression of MMP-2, which inactivates SDF (which is normally able to inhibit HIV infection). ${ }^{(58)}$ Other examples of bacterial and parasitic expression or activation of host MMPs were listed in the section above. As yet there is little evidence that chemokine degradation and antagonist produc- tion are involved in the pathogenesis of microbial organisms, rather than being a side effect of MMP activity induced for an alternative role, yet this may be an effective mechanism by which a range of microbes regulate host inflammatory responses.

Induction of anti-chemokine antibodies. A third potential host anti-inflammatory response that microbes may take advantage of is the transient production of antichemokine antibodies. A transient anti-self reaction towards pro-inflammatory chemokines has been observed during severe inflammation, ${ }^{(59)}$ although as yet it is not known whether the production of neutralising antibodies is strong enough to contribute to the downregulation of inflammation. If microbes were able to stimulate or enhance this host antiinflammatory mechanism, they could indirectly inhibit chemokine function. This result could be achieved in a number of ways. Firstly, anti-self anti-chemokine antibody production could be non-specifically enhanced, such as through the production of super-antigens, ${ }^{(60,61)}$ triggering a strong inflammatory environment, ${ }^{(62)}$ or through the destruction of tolerogenic cells ${ }^{(63,64)}$ (mechanisms occurring during infection by several important pathogens). Secondly, anti-self antibody production against chemokines could be specifically enhanced. It is possible that the vCks produced have enough homology to host chemokines that any antibody response against the viral products is cross-reactive to the host chemokine. This pathway is particularly feasible as it could allow the circumvention of T cell tolerance towards host chemokines, by using helper $\mathrm{T}_{\mathrm{H}^{-}}-2$ cells specific for unique viral epitopes in the vCk to stimulate B cells specific for homologous epitopes. Theoretically, a vCk receptor antagonist could therefore directly antagonise the receptor, while simultaneously indirectly causing the neutralisation of the ligand via production of anti-ligand antibodies. While all of these mechanisms are theoretically feasible, no studies have yet examined the relevance of anti-chemokine antibody production as a pathogenic mechanism.

\section{The logic behind the madness}

Various microorganisms have exploited the chemokine system for several different purposes, using the mechanisms outlined above. Most obviously, exploitation is able to allow immune evasion, and therefore prolonged persistence in the host. Additionally, chemokine subversion has been used to directly enhance microbial replication and spread. Both of the objectives have been achieved through manipulating the properties of chemokines as chemotactic agents, and as messengers with a wide variety of alternative roles.

\section{Immune evasion through modifying chemotaxis}

The most obvious way in which microbes can take advantage of the chemokine system is to prevent chemotaxis of host

\section{BioEssays 25.5}


leukocytes to allow immune evasion. This can be an achieved either through preventing the inflammatory influx, or through biasing the influx to a less effective composition.

Prevention of the inflammatory influx is the most direct approach, requiring only non-specific neutralisation of a wide variety of chemokines. The host uses such a method to quell excessive inflammation by preventing the influx of inflammatory leukocytes, using the red blood cell antigen DARC, which is able to bind a range of chemokines, but does not give activation of the receptor. DARC ${ }^{-/-}$mice show this is indeed a viable mechanism, with excessive inflammation observed in response to LPS. ${ }^{(65)}$ This approach is exemplified by the Molluscum contagiosum virus (MCV) vCk MC148R. This vCk is able to act as a receptor antagonist for many $\mathrm{CC}$ and $\mathrm{CXC}$ receptors. ${ }^{(16)}$ As such it is able to potently inhibit chemotaxis of neutrophils, macrophages and lymphocytes. This property may account for the conspicuous absence of inflammatory cells in MCV lesions, and the delayed or absent inflammatory response. ${ }^{(16,18)}$ However, no viral mechanism is completely non-discriminating, as MC148R is not able to antagonise CCR10 or CXCR6. ${ }^{(18)}$ The other example of a broad-based chemokine neutralisation, poxvirus vCkBP-II, is able to neutralise a wide variety of chemokines, but has very complex binding dynamics, so that the neutralisation is dependent on the mixture of constituents. ${ }^{(66)}$ Thus, while relying on general immuno-suppression, broad-based antagonism/ neutralisation may be simultaneously working to a certain extent in the same fashion as the specific antagonists-by biasing the immune response towards a non-threatening response.

Discrete cellular populations of leukocytes are often able to recruit leukocytes of a similar immunological predisposition, while reducing the influx of cells with immunologically opposed properties. In addition to biasing the cellular population, this results in a bias in the local environment (such as through a shift in cytokine expression), which often makes the initial composition of the inflammatory influx critical to, and defining of, the subsequent immune response. The phenomenon is best understood with the paradigm of self-promoting $\mathrm{T}_{\mathrm{H}^{-1}}$ or $\mathrm{T}_{\mathrm{H}}-2$ responses, ${ }^{(67-69)}$ but is likely to also occur with other cellular populations, at both finer and broader levels.

Therefore, microbes can distort the immunological environment of the infection site with a relatively minor shift in the initial influx, which results in the predominance of an ineffective immunological response over the 'normal' effective response. This result can be accomplished in two main ways by altering chemotaxis. Firstly, by reducing the influx of the effective response to allow the ineffective response to dominate, and secondly by increasing the influx of the ineffective response so that it overwhelms the effective response. A key example is KSHV. The most effective host response against KSHV infection is $T_{\mathrm{H}^{-1}}$ biased immunity. ${ }^{(17)}$ The expression of VMIPII by $\mathrm{KSHV}$-infected cells creates a bias towards a $\mathrm{T}_{\mathrm{H}}-2$ immune response, thereby promoting immune evasion. ${ }^{(70)}$ VMIPII achieves this function using both methods outlined above. Firstly, vMIPII is a competitive antagonist for CCR1, CCR2, CCR5, CXCR3 and CXCR4. ${ }^{(13)}$ Secondly, vMIPII is a potent agonist for CCR3 and CCR8, and a weak agonist of CXCR2. ${ }^{(13)}$ In addition, KSHV vCk vMIPI is a selective agonist for CCR8. ${ }^{(71)}$ This combination results in the inhibition of $\mathrm{T}_{\mathrm{H}^{-1}}$ cellular influx (mediated by CCR1, CCR5 and CXCR3), and the enhancement of an eosinophilic, ${ }^{(13)}$ monocytic ${ }^{(70)}$ and $\mathrm{T}_{\mathrm{H}^{-}}$-2 cellular influx ${ }^{(70)}$ (which respond to CCR3 and CCR8). The created bias is self-propagating, as activated $\mathrm{T}_{\mathrm{H}}-2$ cells activate and recruit $\mathrm{T}_{\mathrm{H}}$-2-biased cells, while simultaneously inhibiting the activation and recruitment of $\mathrm{T}_{\mathrm{H}^{-1}}-$ biased cells. ${ }^{(68)}$

Another example is the hookworm Necator americanus, which is normally cleared by an effective $\mathrm{T}_{\mathrm{H}}-2$ / eosinophilic response. In order to reduce the influx of eosinophils, basophils, mast cells and $\mathrm{T}_{\mathrm{H}}-2$ cells via eotaxin acting on CCR3, $N$. americanus secretes a metalloprotease that degrades eotaxin. This response is able to reduce the effective $T_{\mathrm{H}^{-}}-2$ / eosinophilic response, resulting in maintenance of the parasite in the host. ${ }^{(56)}$

\section{Immune evasion through alternative chemokine properties}

The role of chemokines in immunity is not solely based on chemotaxis, and several chemokines have been implicated to have immune-stimulatory and immune-deviating properties and roles in apoptosis. ${ }^{(8)}$ Therefore, modification of the chemokine system could bias the immune response towards the ineffective response by distorting the activation status of disparate cell populations. Examples of this mechanism include KSHV vCks vMIPI and vMIPII, which as previously stated act as agonists for CCR8. ${ }^{(70)}$ As well as promoting an influx of $\mathrm{T}_{\mathrm{H}}-2$ cells, CCR8 activation has been shown to inhibit apoptosis of $\mathrm{T}_{\mathrm{H}^{-}} 2$ cells and increase their activation status, further biasing the existing cell infiltrate to a $\mathrm{T}_{\mathrm{H}}-2$ phenotype. ${ }^{(71)}$ A contrasting example may occur with vCks that can activate CCR5, which have been shown to enhance apoptosis of lymphocytes. ${ }^{(72)}$ Various microbes can induce IL-8 (or produce vIL-8 homologs), which has been shown to reduce the anti-viral activity of IFN $\alpha$, also aiding immune evasion. ${ }^{(73)}$

\section{Aiding microbial propagation through chemotaxis}

An alternative reason why microbes alter the chemotaxis of host cells through exploiting the chemokine system is to aid in propagation. By using the chemokine system to actively recruit permissive cells, the microbe ensures a larger host reservoir to allow enhanced replication. Alternatively, the chemokine system can be used to allow the dissemination of infected cells to regions where other permissive cells are located, resulting in systemic spread from the local site of infection. 
There are many examples of microbes using these mechanisms. Examples of recruitment include the use of the HIV protein Tat (with homology to CC chemokines) that recruits permissive macrophages and monocytes by activation of CCR2 and CCR3, ${ }^{(11)}$ the expression of the HHV6 vCk U83 to recruit permissive lymphocytes, ${ }^{(74)}$ and the expression of vIL- 8 by MDV-infected cells to recruit permissive mononuclear cells. $^{(14)}$

A good example of both recruitment and dissemination is that of CMV. CMV infection upregulates IL- ${ }^{(73)}$ and $\mathrm{GRO} \alpha{ }^{(75)}$ and leads to production of VCXCL1 (viral homolog of IL-8 ${ }^{(15)}$ ). These molecules enhance the recruitment of neutrophils via CXCR1/2. As neutrophils are permissive for CMV replication, the recruited cells are infected. ${ }^{(15)}$ The CMV-infected cells then upregulate CXCR1, ${ }^{(73)}$ and express the vCkRs US28, US27 and UL33. ${ }^{(16)}$ CXCR1 upregulation allows the infected cells to migrate towards endogenous IL-8, ${ }^{(76)}$ and US28 may allow chemotaxis towards various endogenous CC chemokines $^{(19)}$ (the roles of US27 and UL33 are still unknown). This aids in the dissemination of infected cells to other sites containing neutrophils. ${ }^{(76)}$ In addition, direct contact between infected neutrophils and endothelial cells during the transendothelial migration (driven by chemokines) results in the infection of endothelial cells. ${ }^{(77)}$

Another example is that of $B$. pertussis. $B$. pertussis causes the upregulation of IL-8, GRO $\alpha$, GRO $\beta$, GRO $\gamma, \mathrm{MCP}-1$ and MIP-1 $\alpha$ in a human cell line, which may be responsible for the recruitment of neutrophils and macrophages observed during infection. ${ }^{\left({ }^{35)}\right.}$ Recruited cells are induced to upregulate CD11b/ CD18 (CR3), which is the receptor for filamentous hemagglutinin, allowing $B$. pertussis to remain bound to the cell to prevent clearance and flushing from the respiratory tract. ${ }^{(35)}$ Pertussis toxin (PT) may aid in this process by inactivating G-protein-coupled receptors (including chemokine receptors), preventing the cells from leaving the infection site, although it must be stressed that a precise role for PT during infection is unclear. $^{(35)}$

\section{Aiding microbial propagation via alternative chemokine roles}

Microbial propagation can also be enhanced by taking advantage of non-chemotactic properties of chemokines, such as angiogenesis. Several vCks (such as vMIPII, Refs. 13,17) and vCkRs (the herpesvirus vCXCR, KSHV ORF-74, Ref. 21) are able to promote angiogenesis, which is able to aid dissemination of the virus and enhance tumour growth (important for the formation of KSHV lesions). Herpesvirus vCXCR (KSHV ORF-74) is also directly implicated in oncogenic transformation, ${ }^{(23)}$ as the constitutive signalling activity (enhanced by the binding of endogenous ligands) of this $v C k R$ aids proliferation of the host cell. ${ }^{(24)}$

CMV also takes advantage of non-chemotactic chemokine properties. As stated above, CMV induces IL-8 expression to enhance neutrophil chemotaxis to the site of infection. While this is a chemotactic use of viral chemokine induction, the produced IL-8 also serves to directly stimulate CMV replication. ${ }^{(76)}$

Another interesting example is that of HIV. HIV uses CXCR4 as a coreceptor for entry into cells. It has previously been shown that SDF-1 is able to inhibit HIV entry into cells by occupying CXCR4 and causing internalisation (receptor desensitisation). A possible counter to this host defensive action is the HIV-dependent enhanced expression of MMP-2, ${ }^{(58)}$ which is able to inactivate SDF-1, ${ }^{(52)}$ and therefore prevent its anti-HIV function.

\section{Conclusions}

Chemokines make up an important defence mechanism in the immune response, as well as functioning as extracellular messengers for a number of immune and non-immune roles. The importance of chemokines to the host immune system is becoming increasingly emphasised by the level of exploitation by pathogens. Pathogens have independently evolved a myriad of ways to reduce the effectiveness of the chemokine system. Indeed, it is likely that many mechanisms that are not yet known to be exploited by microbial pathogens are simply awaiting discovery with further advances in research. Microbial pathogens appear to not only inactivate the chemokine network, but also to use the host system to their advantage. With further research into the roles of chemokines in infection, and into the ways in which microbes sabotage the host system, we may also learn to successfully manipulate the chemokine system, to aid in the war against contagion.

\section{References}

1. Finlay BB, Falkow S. Common themes in microbial pathogenicity revisited. Microbiol Mol Biol Rev 1997;61:136-169.

2. Haig DM. Subversion and piracy: DNA viruses and immune evasion. Res Vet Sci 2001;70:205-219.

3. Alcami A, Koszinowski UH. Viral mechanisms of immune evasion. 2000; 21:447-455

4. Mackay CR. Chemokines: immunology's high impact factors. Nat Immunol 2001;2:95-101.

5. Baggiolini M. Chemokines and leukocyte traffic. Nature 1998;392:565568.

6. Koopmann W, Ediriwickrema C, Krangel MS. Structure and function of the glycosaminoglycan binding site of chemokine macrophage-inflammatory protein-1 beta. J Immunol 1999;163:2120-2127.

7. Baggiolini M, Dewald B, Moser B. Human chemokines: an update. Annu Rev Immunol 1997;15:675-705

8. Gale LM, McColl SR. Chemokines: extracellular messengers for all occasions? Bioessays 1999;21:17-28.

9. Bodaghi B, Jones TR, Zipeto D, Vita C, Sun L, Laurent L, ArenzanaSeisdedos F, Virelizier JL, Michelson S. Chemokine sequestration by viral chemoreceptors as a novel viral escape strategy: withdrawal of chemokines from the environment of cytomegalovirus-infected cells. J Exp Med 1998; 188:855-866.

10. Liu L, Lalani A, Dai E, Seet B, Macauley C, Singh R, Fan L, McFadden G, Lucas A. The viral anti-inflammatory chemokine-binding protein M-T7 reduces intimal hyperplasia after vascular injury. J Clin Invest 2000;105: $1613-1621$

\section{BioEssays 25.5}


11. Albini A, et al. HIV-1 Tat protein mimicry of chemokines. Proc Nat Acad Sci USA 1998;95:13153-13158

12. Rao SP, Hayashi T, Catanzaro A. Identification of a chemotactic, MCP-1like protein from Mycobacterium avium. FEMS Immun Med Microbio 2002;33:115-124

13. Crump MP, Elisseeva E, Gong JH, Clark-Lewis I, Sykes BD. Structure/ function of human herpesvirus-8 MIP-II (1-71) and the antagonist Nterminal segment (1-10). FEBS Letters 2001;489:171-175.

14. Parcells MS, et al. Marek's disease virus (MDV) encodes an interleukin-8 homolog (VIL-8): characterization of the VIL-8 protein and a VIL-8 deletion mutant MDV. J Virol 75 2001:11:5159-5173.

15. Penfold MET, Dairaghi DJ, Duke GM, Saederup N, Mocarski ES, Kemble GW, Schall TJ. Cytomegalovirus encodes a potent alpha chemokine. Proc Nat Acad Sci USA 1999;96:9839-9844

16. Mahalingam S, Clark K, Matthaei KI, Foster PS. Antiviral potential of chemokines. Bioessays 2001;23:428-435.

17. Schultz TF. Kaposi's sarcoma-associated herpesvirus (human herpesvirus-8). J Gen Virol 1998;79:1573-1591.

18. Lüttichau HR, Clark-Lewis I, Gerstoft J, Schwartz TW. The herpesvirus 8-encoded chemokine VMIP-II, but not the poxvirus-encoded chemokine MC148, inhibits the CCR10 receptor. Eur J Immunol 2001;31:12171220.

19. Billstrom MA, Johnson GL, Avdi NJ, Worthen GS. Intracellular signaling by the chemokine receptor US28 during human cytomegalovirus infection. J Virol 1998;72:5535-5544.

20. Gershengorn MC, Geras-Raaka E, Varma A, Clark-Lewis I. Chemokines activate Kaposi's sarcoma-associated herpesvirus G protein-coupled receptor in mammalian cells in culture. J Clin Invest 1998;102:14691472.

21. Bais C, et al. G-protein-coupled receptor of Kaposi's sarcoma-associated herpesvirus is a viral oncogene and angiogenesis activator Nature 1998;391:86-89.

22. Holst PJ, Rosenkilde MM, Manfra D, Chen S, Wiekowshi MT, Holst B, Cifire F, Lipp M, Schwartz TW, Lira SA. Tumorigenesis induced by the HHV8-encoded chemokine receptor requires ligand modulation of high constitutive activity. J Clin Invest 2001;108:1789-1796.

23. Arvanitakis L, Geras-Raaka E, Varma A, Gershengorn MC, Cesarman E. Human herpesvirus KSHV encodes a constitutively active Gprotein-coupled receptor linked to cell proliferation. Nature 1997;385: $347-350$

24. Casarosa P, Bakker RA, Verzijl D, Navis M, Timmerman H, Leurs R, Smi MJ. Constitutive signaling of the human cytomegalovirus-encoded chemokine receptor US28. J Biol Chem 2001;276:1133-1137.

25. Kirshner JR, Staskus K, Haase A, Lagunoff M, Ganem D. Expression of the open reading frame 74 (G-protein-coupled receptor) gene of Kaposi's sarcoma (KS)-associated herpesvirus: implications for KS pathogenesis. J Virol 1999;73:6006-6014.

26. Cesarman E, Nador RG, Bai F, Bohenzky RA, Russo JJ, Moore PS Chang Y, Knowles DM. Kaposi's sarcoma-associated herpesvirus contains $G$ protein-coupled receptor and cyclin D homologs which are expressed in Kaposi's sarcoma and malignant lymphoma. J Virol 1996; 70:8218-8223.

27. Geras-Raaka E, Varma A, Ho H, Clark-Lewis I, Gershengorn MC. Human Interferon-inducible Protein 10 (IP-10) Inhibits Constitutive Signaling of Kaposi's Sarcoma-associated Herpesvirus. J Exp Med 1998;188:405408

28. Meissner U, Blum H, Schnare M, Rollinghoff M, Gessner A. A soluble form of the murine common gamma chain is present at high concentrations in vivo and suppresses cytokine signaling. Blood 2001;97:183191

29. Parry CM, Simas JP, Smith VP, Stewart CA, Minson AC, Efstathiou S Alcami A. A broad spectrum secreted chemokine binding protein encoded by a herpesvirus. J Exp Med 2000;191:573-578.

30. van Berkel V, Barrett J, Tiffany HL, Fremont DH, Murphy PM, McFadden G, Speck SH, Virgin HI. Identification of a gammaherpesvirus selective chemokine binding protein that inhibits chemokine action. J Virol 2000; 74:6741-6747.

31. Alcami A, Symons JA, Collins PD, Williams TJ, Smith GL. Blockade of chemokine activity by a soluble chemokine binding protein from vaccinia virus. J Immunol 1998;160:624-633.
32. Murayama T, Ohara Y, Obuchi M, Khabar KSA, Higashi H, Mukaida N Matsushima K. Human cytomegalovirus induces interleukin-8 production by a human monocytic cell line, THP-1, through acting concurrently on AP-1 and NF-kappaB-binding sites of the interleukin-8 gene. J Virol 1997;71:5692-5695.

33. Eliopoulos AG, Gallagher NJ, Blake SMS, Dawson CW, Young LS Activation of the p38 Mitogen-activated Protein Kinase Pathway by Epstein-Barr Virus-encoded Latent Membrane Protein 1 coregulates Interleukin-6 an Interleukin-8 production. J Biol Chem 1999;274:1608516096.

34. Yamada H, Aihara T, Okabe S. Mechanism for Helicobacter pylori stimulation of interleukin-8 production in a gastric epithelial cell line (MKN 28): roles of mitogen-activated protein kinase and interleukin-1beta. Biochem Pharm 2001;61:1595-1604.

35. Belcher CE, Drenkow J, Kehoe B, Gingeras TR, McNamara N, Lemjabbar $\mathrm{H}$, Basbaum $\mathrm{C}$, Relman DA. The transcriptional responses of respiratory epithelial cells to Bordetella pertussis reveal host defensive and pathogen counter-defensive strategies. Proc Nat Acad Sci USA 2000;97:13847-13852

36. Jefferson KK, Smith MF Jr, Bobak DA. Roles of intracellular calcium and NF-kappa B in the Clostridium difficile toxin A-induced up-regulation and secretion of IL-8 from human monocytes. J Immunol 1999;163:51835191.

37. Warny M, Keates AC, Keates S, Castagliuolo I, Zacks JK, Aboudola S, Qamar A, Pothoulakis C, LaMont JT, Kelly CP. p38 MAP kinase activation by Clostridium difficile toxin A mediates monocyte necrosis, IL-8 production, and enteritis. J Clin Invest 2000;105:1147-1156.

38. Milne RS, Mattick C, Nicholson L, Devaraj P, Alcami A, Gompels UA. RANTES binding and down-regulation by a novel human herpesvirus- 6 beta chemokine receptor. J Immunol 2000;164:2396-2404.

39. Smith AM, Guzman CA, Walker MJ. The virulence factors of Bordetella pertussis: a matter of control. FEMS Microbiol Rev 2000;25: 309-333

40. Cooper JA Jr, Ridgeway AL, Pearson J, Culbreth RR. Attenuation of interleukin 8-induced nasal inflammation by an inhibitor peptide. Am J Respir Crit Care Med 2001;163:1198-1205.

41. Cooper JA Jr, Carcelen R, Culbreth R. Effects of Influenza A nucleoprotein on polymorphonuclear neutrophil function. J Injectious Dis 1996; 173:279-284

42. Kuschert GS, Coulin F, Power CA, Proudfoot AE, Hubbard RE, Hoogewerf AJ, Wells TN. Glycosaminoglycans interact selectively with chemokines and modulate receptor binding and cellular responses. Biochemistry 1999;38:12959-12968.

43. Hirose J, Kawashima H, Yoshie O, Tashiro K, Miyasaka M. Versican interacts with chemokines and modulates cellular responses. J Biol Chem 2001;276:5228-5234.

44. Van den Steen PE, Opdenakker G, Wormald MR, Dwek RA, Rudd PM Matrix remodelling enzymes, the protease cascade and glycosylation. Biochimica Biophysica Acta 2001;1528:61-73.

45. Tsuda H, Yamada S, Miyazono H, Morikawa K, Yoshida K, Goto F, Tamura J, Neumann KW, Ogawa T, Sugahara K. Substrate specificity studies of Flavobacterium chondroitinase $\mathrm{C}$ and heparitinases towards the glycosaminoglycan-protein linkage region. Eur J Biochem 1999;262: $127-133$

46. Godavarti R, Davis M, Venkataraman G, Cooney C, Langer R, Sasisekharan R. Heparinase III from Flavobacterium heparinum: cloning and recombinant expression in Escherichia coli. Biochem Biophys Res Commun 1996;225:751-758

47. Su H, Blain F, Musil RA, Zimmermann JJ, Gu K, Bennett DC. Isolation and expression in Escherichia coli of hepB and hepC, genes coding for the glycosaminoglycan-degrading enzymes heparinase II and heparinase III, respectively, from Flavobacterium heparinum. Appl Environ Microbiol 1996;62:2723-2734.

48. Santala A, Saarinen J, Kovanen P, Kuusela P. Activation of interstitial collagenase, MMP-1, by Staphylococcus aureus cells having surfacebound plasmin: a novel role of plasminogen receptors of bacteria. FEBS Lett 1999;461:153-156

49. Choi BK, Jung JH, Suh HY, Yoo YJ, Cho KS, Chai JK, Kim CK. Activation of matrix metalloproteinase-2 by a novel oral spirochetal species Treponema lecithinolyticum. J Periodontol 2001;72:1594-1600. 
50. Price NM, Farrar J, Tran TT, Nguyen TH, Tran TH, Friedland JS. Identification of a matrix-degrading phenotype in human tuberculosis in vitro and in vivo. J Immun 2001;166:4223-4230.

51. Panagakos FS, O'Boskey JFJ, Rodriguez E. Regulation of pulp cell matrix metalloproteinase production by cytokines and lipopolysaccharides. J Endod 1996;22:358-361.

52. McQuibban GA, Butler GS, Gong JH, Bendall L, Power C, Clark-Lewis I, Overall CM. Matrix metalloproteinase activity inactivates the CXC chemokine stromal cell-derived factor-1. J Biol Chem 2001;276:4350343508 .

53. McQuibban GA, Gong JH, Tam EM, McCulloch CAG, Clark-Lewis I, Overall CM. Inflammation dampened by Gelatinase A cleavage of monocyte chemoattractant protein-3. Science 2000;289:1202-1206.

54. McColl SR, Clark-Lewis I. Inhibition of murine neutrophil recruitment in vivo by CXC chemokine receptor antagonists. J Immunol 1999;163: 2829-2835.

55. Loetscher P, Gong JH, Dewald B, Baggiolini M, Clark-Lewis I. Nterminal peptides of stromal cell-derived factor-1 with CXC chemokine receptor 4 agonist and antagonist activities. J Biol Chem 1998;273: 22279-22283.

56. Culley FJ, Brown A, Conroy DM, Sabroe I, Pritchard DI, Williams TJ. Eotaxin is specifically cleaved by hookworm metalloproteases preventing its action in vitro and in vivo. J Immunol 2000;165:6447-6453.

57. Van den Steen PE, Proost P, Wuyts A, Van Damme J, Opdenakker G. Neutrophil gelatinase B potentiates interleukin-8 tenfold by aminoterminal processing, whereas it degrades CTAP-III, PF-4, and GRO-alpha and leaves RANTES and MCP-2 intact. Blood 2000;96:2673-2681.

58. Johnston JB, Jiang Y, van Marle G, Mayne MB, Ni W, Holden J, McArthur $\mathrm{JC}$, Power $\mathrm{C}$. Lentivirus infection in the brain ilnduces matrix metalloproteinase expression: role of envelope diversity. J Virol 2000;74:7211-7220.

59. Youssef S, Maor G, Wildbaum G, Grabie N, Gour-Lavie A, Karin N. C-C chemokine-encoding DNA vaccines enhance breakdown of tolerance to their gene products and treat ongoing adjuvant arthritis. J Clin Invest 2000;106:361-371

60. Krakauer T. Immune response to staphylococcal superantigens. Immunol Res 1999;20:163-173.

61. Schiffenbauer J, Soos J, Johnson H. The possible role of bacterial superantigens in the pathogenesis of autoimmune disorders. Immunol Today 1998;19:117-120.

62. Owens T, Babcock A. Immune response induction in the central nervous system. Front Biosci 2002;1:d427-d438.

63. Morse SS, Sakaguchi N, Sakaguchi S. Virus and autoimmunity: induction of autoimmune disease in mice by mouse $T$ lymphotropic virus (MTLV) destroying CD4 + T cells. J Immunol 1999;162:5309-5316.

64. Arkwright PD, Abinun M, Cant AJ. Autoimmunity in human primary immunodeficiency diseases. Blood 2002;99:2694-2702.

65. Dawson TC, Lentsch AB, Wang Z, Cowhig JE, Rot A, Maeda N, Peiper SC. Exaggerated response to endotoxin in mice lacking the Duffy antigen/receptor for chemokines (DARC). Blood 2000;96:1681-1684.

66. Burns JM, Dairaghi DJ, Deitz M, Tsang M, Schall TJ. Comprehensive mapping of poxvirus $\mathrm{vCCl}$ chemokine-binding protein. J Biol Chem 2002;277:2785-2789.

67. Neurath MF, Finotto S, Glimcher LH. The role of Th1/Th2 polarization in mucosal immunity. Nat Med 2002;8(6):567-573

68. Glimcher LH, Murphy KM. Lineage commitment in the immune system: the T helper lymphocyte grows up. Genes Dev 2000;14:1693-1711.
69. Jankovic D, Liu Z, Gause WC. Th1- and Th2-cell commitment during infectious disease: asymmetry in divergent pathways. Trends Immuno 2001;22:450-457.

70. Sozzani S, et al. The viral chemokine macrophage inflammatory protein-II is a selective Th2 chemoattractant. Blood 1998;92:4036-4039.

71. Endres MJ, Garlisi CG, Xiao H, Shan L, Hedrick JA. The Kaposi's sarcoma-related Herpesvirus (KSHV)-encoded chemokine VMIP-I is a specific agonist for the CC chemokine receptor (CCR)8. J Exp Med 1999;189:1993-1998

72. Mellado M, de Ana AM, Moreno MC, Martinez C, Rodriguez-Frade JM. A potential immune escape mechanism by melanoma cells through the activation of chemokine-induced T cell death. Curr Biol 2001;11:691696

73. Murayama T, Mukaida N, Khabar KSA, Matsushima K. Potential involvement of IL-8 in the pathogenesis of human cytomegalovirus infection. J Leukocyte Biol 1998;64:62-67.

74. Zou P, Isegawa Y, Haque M, Horiguchi Y, Yamanishi K. Human Herpesvirus 6 open reading frame U83 encodes a functional chemokine. J Viro 1999;73:5926-5933.

75. Grundy JE, Lawson KM, MacCormac LP, Fletcher JM, Yong KL. Cytomegalovirus-infected endothelial cells recruit neutrophils by the secretion of C-X-C chemokines and transmit virus by direct neutrophilendothelial contact and during neutrophil transendothelial migration. J Infect Diseases 1998;177:1465-1474.

76. Mahalingam S, Karupiah G. Chemokines and chemokine receptors in infectious diseases. Immunol Cell Biol 1999;77:469-475

77. Craigen JL, Yong KL, Jordan NJ, MacCormac LP, Westwick J, Akbar AN Grundy JE. Human cytomegalovirus infection up-regulates interleukin-8 gene expression and stimulates neutrophil transendothelial migration. Immunology 1997;92:138-145

78. Graham KA, Lalani AS, Macen JL, Ness TL, Barry M, Liu LY, Lucas A, Clark-Lewis I, Moyer RW, McFadden G. The T1/35kDa family of poxvirussecreted proteins bind chemokines and modulate leukocyte influx into virus-infected tissues. Virology 1997;229:12-24.

79. Cao JX, Gershon PD, Black DN. Sequence analysis of HindIII Q2 fragment of capripoxvirus reveals a putative gene encoding a Gprotein-coupled chemokine receptor homologue. Virology 1995;209: 207-212.

80. Martin WJ. Chemokine receptor-related genetic sequences in an african green monkey simian cytomegalovirus-derived stealth virus. Exp Mo Pathol 2000;2000:1.

81. Isegawa Y, Ping Z, Nakano K, Sugimoto N, Yamanishi K. Human Herpesvirus 6 open reading frame U12 encodes a functional betachemokine receptor. J Virol 1998;72:6104-6112

82. Martin WJ. Melanoma growth stimulatory activity (MGSA/GRO-alpha) chemokine genes incorporated into an African green monkey simian cytomegalovirus-derived stealth virus. Exp Mol Pathol 1999;66: $15-18$

83. Fleming P, Davis-Poynter N, Degli-Esposti M, Densley E, Papadimitriou J, Shellam G, Farrell H. The murine cytomegalovirus chemokine homolog, $\mathrm{m} 131 / 129$, is a determinant of viral pathogenicity. J Virol 1999;73: 6800-6809.

84. Saederup N, Aguirre SA, Sparer TE, Bouley DM, Mocarski ES. Murine cytomegalovirus CC chemokine homolog MCK-2 (m131-129) is a determinant of dissemination that increases inflammation at initial sites of infection. J Virol 2001;75:9966-9976.

\section{BioEssays 25.5}

